\title{
(Vapor + Liquid) Equilibrium for Mixtures Ethanol + Biodiesel from Soybean Oil and Frying Oil
}

\author{
Pollyana M. S. Kalvelage ${ }^{\mathrm{a}}$, Allan A. Albuquerque ${ }^{\mathrm{b}}$, António A. C. Barros ${ }^{\mathrm{c}}$, Sávio L. Bertoli ${ }^{\mathrm{a}}$ \\ ${ }^{a}$ Blumenau Regional Foundation. Av. São Paulo, 3250, Zipcode 89030-000, Blumenau, SC, Brazil \\ ${ }^{b}$ Fuel Laboratory, Chemical Engineering Department, Federal University of Pernambuco, Av. Prof. Artur de Sá S/N, \\ Zipcode 50740-521, Recife, PE, Brazil \\ ${ }^{\mathrm{c}}$ Department of Engineering and Technology, Polytechnic Institute of Technology and Sciences, Av. Luanda Sul S/N, \\ Luanda, Angola \\ E-mail: *allan.almeida@ufpe.br
}

Received 22 January 2017, Revised 27 May 2017, Accepted 08 June 2017

\begin{abstract}
In order to provide new isobaric vapor-liquid equilibrium (VLE) data for ethanol-biodiesel systems, experimental boiling points for mixtures of ethanol + biodiesel from soybean oil (SB) and frying oil (FB) were measured. UNIFAC and NRTL models were used to predict and correlate the data, in order to better represent the VLE in process simulation. VLE data were measured with a Fischer type ebulliometer. Reliability and reproducibility were evaluated with VLE data for ethanol + water system at $101.32 \mathrm{kPa}$. These data also proved to be thermodynamically consistent based on the area test. The boiling temperatures for ethanol + biodiesel systems agreed with other results reported at same pressure for SB and for biodiesel from sunflower seed oil (SSB). The thermodynamic modelling using the NRTL model obtained lower AAD values than those from UNIFAC, assuring better safety in the design and simulations steps of a biodiesel production plant.
\end{abstract}

\section{Keywords: Biodiesel; Ethanol; NRTL; UNIFAC; Vapor-liquid equilibrium.}

\section{Introduction}

Biodiesel is a renewable fuel composed of alkyl esters produced mainly from vegetable oils and animal fats through the transesterification reaction applied to the triacylglycerols [1]-[3]. However, the products of these reactions incorporate many impurities, requiring the use of secondary purification processes, especially, processes related to liquid-liquid extraction, distillation and separation by gravity present in the most used alkali-catalyzed transesterification route [4],[5].

In order, to improve the performance of the biodiesel production and purification processes, the equilibrium stages conditions involved in each step of these processes must usually be identified. Therefore, the study of vaporliquid equilibrium (VLE) found in the alcohol recovery and biodiesel purification processes are very important in order to obtain a successful design and operation analysis for the distillation column. This separation is governed by the difference in boiling point between the alcohol and the alky esters [6],[7].

When ethanol is used instead of methanol close attention is required in the biodiesel purification process, mainly, due to the greater solubility of ethyl alcohol in the biodiesel phase. Because the ethanol is more soluble than methanol in this phase, it is more difficult to meet the market specifications after the vapor-liquid separation [8][11]. For this reason many biodiesel producers prefer to use methanol, which is also cheaper than ethanol [12],[13]. On the other hand, some countries such as Brazil, produce a large amount of ethanol, so prefer to use the cheaper ethanol as a way to make the biodiesel production more economically competitive than diesel [7],[14]. In addition, the use of ethanol instead methanol is encouraged since it is a renewable fuel and also lesser toxic. Furthermore, few studies have reported on the use of VLE data for ethanolbiodiesel systems close to ambient pressure [6],[11],[15]. These studies are not only important for a better representation of the VLE data in distillation columns and flash drums, but also as they show that a blend alkyl estersethanol can be used as a fuel to reduce the ignition delay and combustion problems due to low ethanol vapor pressure [15].

In order to increase the amount of VLE data for ethanolbiodiesel systems, we decided to measure experimental boiling points for mixtures of ethanol + biodiesel from soybean oil (SB) and from frying oil (FB), both at 101.32 $\mathrm{kPa}$. In addition, two models, the Universal FunctionalGroup Activity Coefficient (UNIFAC) for prediction and the Non-Random Two-Liquid (NRTL) for thermodynamic modelling, were used in order to represent the VLE for these mixtures in the process simulation [16],[17].

\section{Materials and Methods \\ 2.1 Chemicals and Biodiesel Preparation}

Merck supplied the methanol and ethanol, with purity of 99.9\% (mass fraction). Distilled water was also used. Soybean oil (Lisa) was bought from a supermarket and was used to produce fatty acid methyl esters (FAME). An alkalisolid catalyzed (6\% of $\mathrm{CaO}$ related to oil mass) transesterification reaction was carried out with a methanol to oil molar ratio of $14: 1$ at $333.15 \mathrm{~K}$ for 2 hours [18]. A $99 \%$ mass purity of esters was obtained for the soybean 
biodiesel. Frying oil was obtained from the restaurant at a local school and was used to produce the fatty acid ethyl esters (FAEE) that compose the FB. The transesterification reaction was carried out in a reactive distillation column using ethanol to oil molar ratio of $6: 1,1 \%$ of $\mathrm{KOH}$ catalyst (mass purity of $98 \%$ ) related to oil mass [19]. The mass purity of esters obtained was higher than $96.5 \%$.

The esters produced and ethanol compositions obtained from the VLE measurements were analyzed by Gas Chromatography (GC) with Flame Ionization Detection IN - GC/FID. The GC was from a model CG-2010 with Auto Injector AOC-5000 from Shimadzu as shown in Table 1.

Table 1. GC conditions for esters produced and compositions obtained in VLE measurements (standard EN 14103).

\begin{tabular}{cc}
\hline Variable & Esters analysis $\mid$ VLE analysis \\
\hline Column & Stabilwax $\mid \mathrm{RTX}-1$ \\
Column dimensions & $(30 \mathrm{~m} \times 0.25 \mathrm{~mm} \times 0.25 \mu \mathrm{m}) \mid(30 \mathrm{~m} \mathrm{x}$ \\
& $0,32 \mathrm{~mm} \times 3 \mu \mathrm{m})$ \\
Detector type & FID \\
Detector temperature & $553.15 \mathrm{~K} \mid 423.15 \mathrm{~K}$ \\
Injector temperature & $523.15 \mathrm{~K} \mid 423.15 \mathrm{~K}$ \\
Carrier gas & Helium \\
Flow rate|injection volume & $1.77 \mathrm{~mL} / \mathrm{min}($ constant $) \mid 500 \mu \mathrm{L}$ \\
Oven temperature & $484.15 \mathrm{~K}(40 \mathrm{~min}) \mid 323.15 \mathrm{~K}(10 \mathrm{~min})$ \\
Split ratio & $1: 50$ \\
\hline
\end{tabular}

\subsection{VLE Apparatus and Procedures}

The vapor-liquid equilibrium data were measured using a Fischer-type ebulliometer (model 602), as shown in Figure $1[20,21]$. This is a dynamic measuring cell of VLE data suitable for non-electrolyte systems and allows the study of mixtures containing substances with a high boiling point. The operation is based on the circulation of the liquid and vapor phases in contact with each other until they reach equilibrium. The temperatures of equilibrium were measured using a PT-100 thermometer with a resolution of $\pm 0.05 \mathrm{~K}$. Samples from the liquid and vapor phases were taken, both through activation of valves, when the equilibrium temperature had been attained. These compositions were analyzed by GC. The Itajaí Basin Alert System Operation Center, located at the Regional University of Blumenau, determined the system ambient pressure $(101.32 \mathrm{kPa})$ at a resolution of $\pm 0.10 \mathrm{kPa}$.

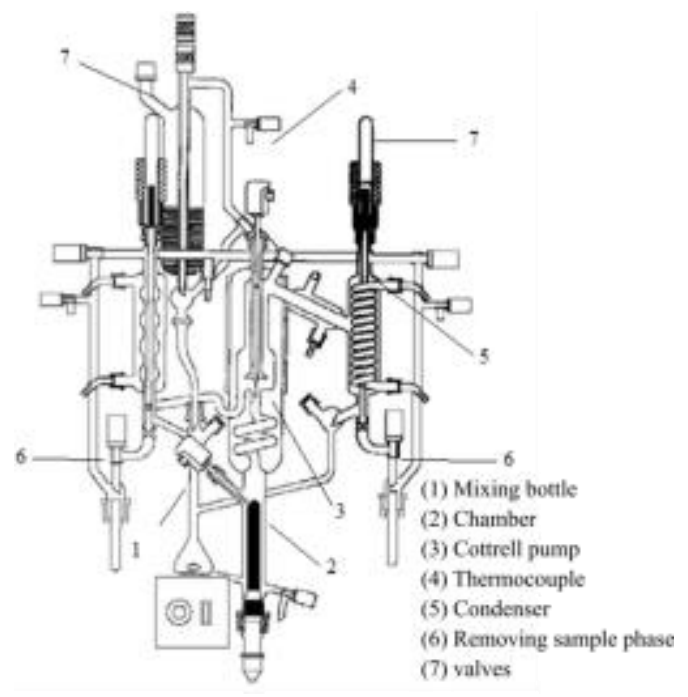

Figure 1. Fisher ebulliometer model 602.

\subsection{Prediction and Thermodynamic Modelling}

A modified Raoult's law was adopted to represent the VLE equilibrium at low pressures according to Eq. (1)

$y_{i} P=x_{i} \gamma_{i} P_{i}^{\text {vap }}$

where $y_{i}$ and $x_{i}$ are component vapor and liquid compositions (mole fraction), while $P$ and $P_{i}^{\text {vap }}$ represent total and component vapor pressures. The liquid-phase nonidealities were calculated based on the component activity coefficient $\left(\gamma_{i}\right)$ [22].

The UNIFAC and NRTL models were used to predict and correlate the $\gamma_{i}$ from the VLE data. The experimental (exp) and calculated (cal) results involved in VLE systems were compared using the average absolute deviation (AAD) according to Eq. (2).

$A \mathrm{~A} D(V)=\frac{1}{N} \sum_{n=1}^{N}\left|V_{n}^{\text {exp }}-V_{n}^{\text {cal }}\right|$

In Eq. (2) $V$ represents the variable temperature $(T)$, pressure $(P)$ or vapor phase composition $(y)$ in mole fraction; $N$ are the total number of experimental points $n$.

The NRTL binary interaction parameters were obtained by minimization of the objective function $(O F)$ adapted from Stragevitch and d'Ávila [23] according to Eq. (3),

$O F=\sum_{n=1}^{N}\left[\left(\frac{P_{n}^{e x p}-P_{n}^{c a l}}{\sigma_{P}}\right)^{2}+\sum_{i=1}^{I}\left(\frac{y_{i, n}^{e x p}-y_{i, n}^{c a l}}{\sigma_{y}}\right)^{2}\right]$

where $\sigma_{P}$ and $\sigma_{y}$ are uncertainties observed in $P$ and $y_{i} ; I$ are the total number of components $i$.

\section{Results and Discussion}

The experimental procedure was evaluated regarding reliability and reproducibility through measurements of VLE data for ethanol + water system at $101.32 \mathrm{kPa}$. These data also proved to be thermodynamically consistent based on the area test from Aspen Plus V8.8 [24],[25]. In addition, these VLE data were compared with other data measured at $101.3 \mathrm{kPa}$, as reported by Iwakabe and Kosuge [26], so that the methodology was validated given the close agreement with the experimental data as depicted in Figure $2 \mathrm{a}$. The temperature $(\mathrm{T})$ results were plotted against ethanol molar fractions in the liquid $\left(\mathrm{x}_{1}\right)$ and vapor $\left(\mathrm{y}_{1}\right)$ phases.

In addition, a thermodynamic modelling using NRTL model was carried out in order to compare the data to VLE diagrams. Agreement between experimental and calculated VLE was satisfactory for the region of measured data, based on $A A D$ values as shown in Table 2. These results were attained using component vapor pressure parameters from Aspen Plus V8.8. Figure $2 \mathrm{~b}$ also shows that the boiling points measured appear to fit better than the dew points. Therefore, we only took into account the data from the saturated liquid phase, since it appears to be more reliable than the data from the dew points.

The boiling temperatures for mixtures of ethanol + SB and ethanol + FB at $101.32 \mathrm{kPa}$ were measured as shown in Table A1 of the Appendix. These data were compared with the VLE data from mixtures ethanol + SB and ethanol + biodiesel from sunflower seed oil (SSB) reported by Silva et al. [11] and Guo et al. [15] at $91.4 \mathrm{kPa}$ and $100 \mathrm{kPa}$, respectively, as shown in Figure $3 \mathrm{a}$ and $3 \mathrm{~b}$. These results demonstrate that the VLE data trend agrees with the 
reported data plotted in ethanol mass fraction in the liquid phase $\left(\mathrm{w}_{1}\right)$. Despite the small differences in pressure, the temperature values are so close as to be in agreement with the small temperature changes found when the pressure was increased from 64.4 to $91.4 \mathrm{kPa}$ in the VLE data, as reported by Silva et al. [11] Furthermore, temperatures for the VLE data were expected to be lower than those studied by Guo et al. [15], since the SSB was composed of ethyl esters, while the SB adopted in our work and by Silva et al. [11] were composed of FAME.

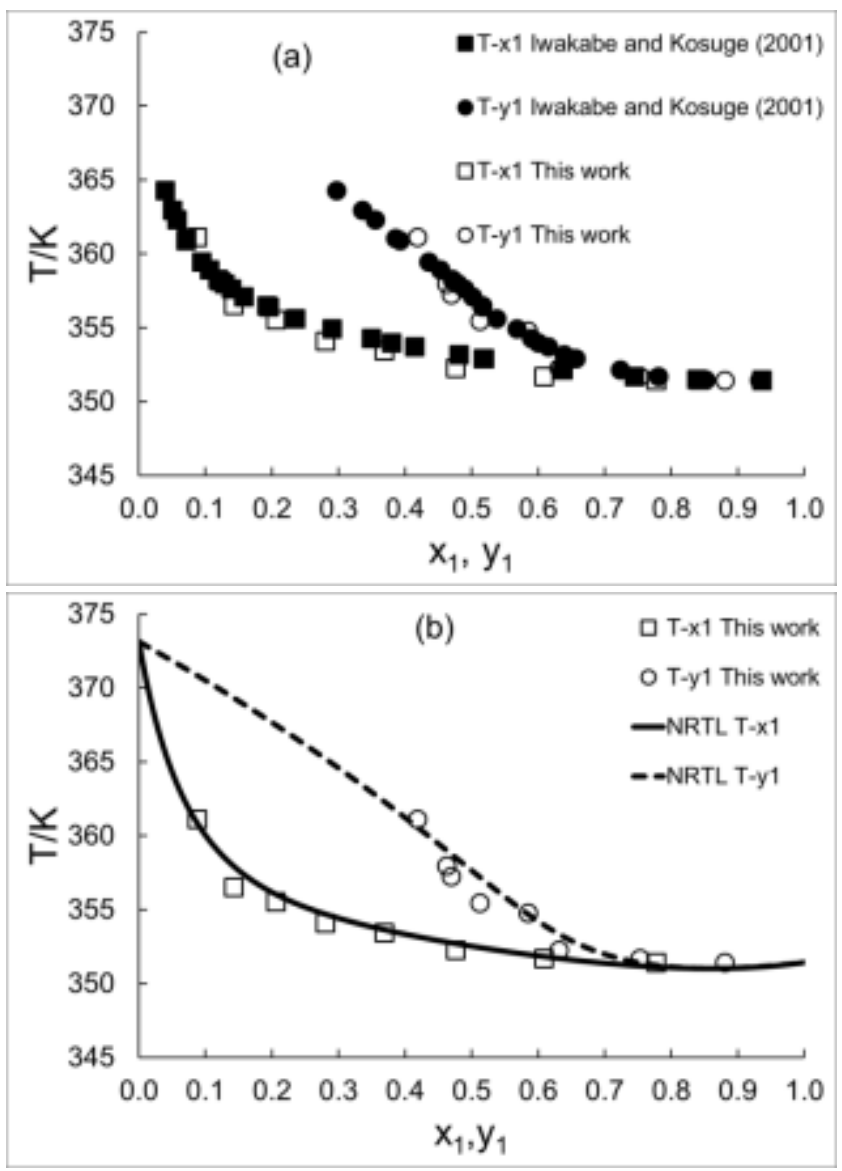

Figure 2. Comparison of VLE data measured for ethanol + water system at $101.32 \mathrm{kPa}(\mathrm{a})$ with reported data [26] at same pressure and (b) with VLE obtained by NRTL model.

Table 2. $A A D^{a}$ values obtained in the VLE prediction and correlation with UNIFAC and NRTL models.

\begin{tabular}{cccccc}
\hline \multirow{2}{*}{$\begin{array}{c}\text { tOH }^{\mathrm{b}} \\
\text { plus }\end{array}$} & \multicolumn{2}{c}{$\mathrm{UNIFAC}$} & \multicolumn{3}{c}{$\mathrm{NRTL}$} \\
\cline { 2 - 6 } & $A A D(P)$ & $A A D(T)$ & $A A D(P)$ & $A A D(y)$ & $A A D(T)$ \\
\hline Water & $\mathrm{N}^{\mathrm{c}} \mathrm{A}^{\mathrm{y}}$ & $\mathrm{N}_{\mathrm{A}} \mathrm{A}^{\mathrm{c}}$ & 1.29 & 0.05 & 0.34 \\
$\mathrm{SB}$ & 6.81 & 1.79 & 1.09 & $\mathrm{~N}^{\mathrm{c}} \mathrm{A}^{\mathrm{c}}$ & 0.27 \\
$\mathrm{FB}$ & 6.93 & 1.81 & 2.44 & $\mathrm{~N}^{\mathrm{c}}$ & 0.61 \\
\hline
\end{tabular}

${ }^{\mathrm{a}} A A D(P)$ and $A A D(T)$ are average absolute deviations in $\mathrm{kPa}$ and $\mathrm{K}$; ${ }^{\mathrm{b}} \mathrm{EtOH}$ represents Ethanol;

${ }^{\mathrm{c}} \mathrm{N} / \mathrm{A}$ means not applied.

Figure $3 b$ shows that despite the FB adopted to be composed of ethyl esters, some temperature values were lower compared to the experimental data reported. This behavior occurred because the frying oil had been used to fry food before it was used to produce biodiesel. Therefore, the combination of high temperatures and presence of air may have produced more volatile undesired products. In addition, some FAEE may have changed their geometry from cis to trans, since the frying oil was derived from soybean oil that contains a high amount of these unsaturated ethyl esters. Temperature values for higher biodiesel content were not shown because the FB had already reached the degradation step.

To better predict and model the VLE data obtained, we calculated the vapor pressures of pure and mixture of esters using the model proposed by Ceriani et al. [27] instead the updated Aspen Plus databank. Our choice was based on three reasons. First this model can be applied to a wide range of temperatures in satisfactory agreement with experimental data. Second the same model is also easily applied to mixtures as shown in Figures $4 \mathrm{a}$ and $4 \mathrm{~b}$. Third binary interactions parameters are not available for all components in Aspen Plus. The composition of fatty acids as specified by Silva et al. [11] and Alcantara et al. [28] for $\mathrm{SB}$ and FB, respectively, were used to calculate the vapor pressure of the alkyl ester mixtures, as shown in Table 3.

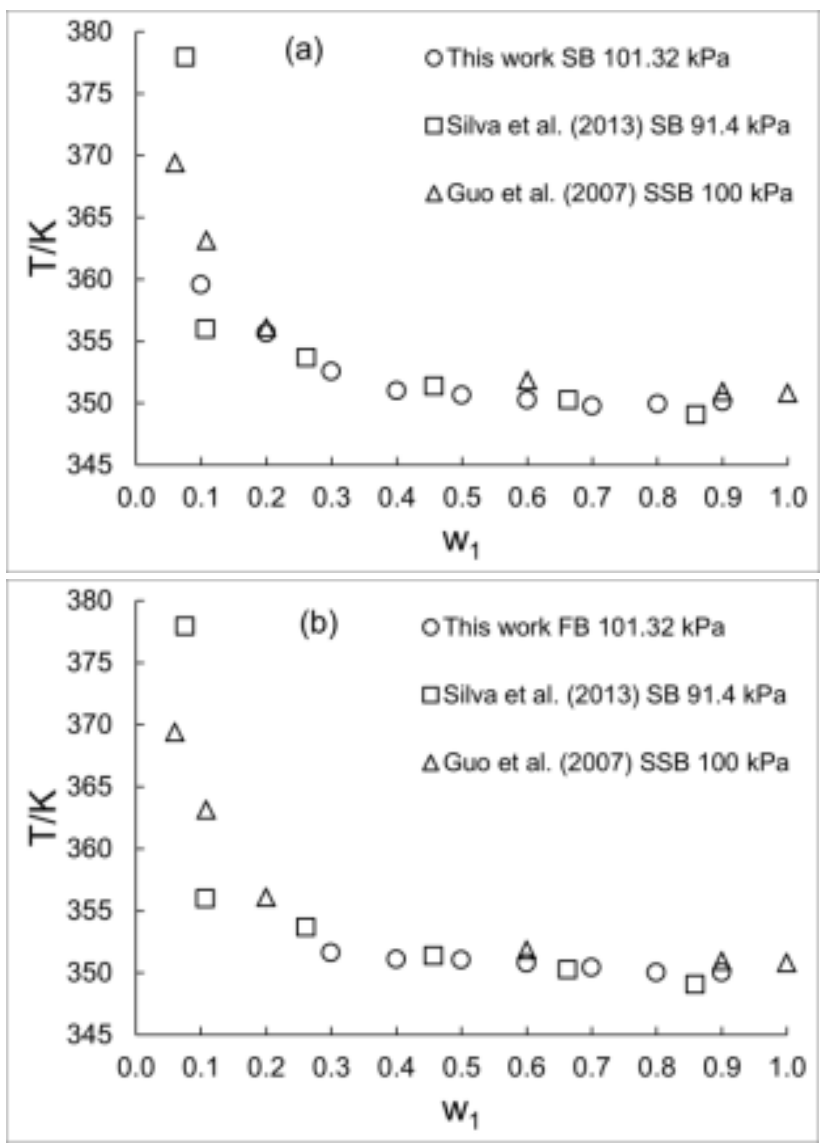

Figure 3. Agreement of VLE data for systems ethanol + biodiesel from soybean oil $(S B)$ and $(b)$ ethanol + biodiesel from frying oil $(F B)$ with boiling points reported [11], [15].

The prediction of the VLE data using UNIFAC was poor for both systems based on $A A D$ values, as shown in Table 2, despite a satisfactory representation in Figure 5.

On the other hand, the thermodynamic modelling using the NRTL model fitted relatively well with only few deviations. In addition, the NRTL curves show the expected behavior of a mixture of components with a high difference in boiling points. Table 2 and Table 4 show the deviations and the NRTL interaction parameters, respectively, including the ethanol + water system. The few deviations using the NRTL model assure more safety in the design and 
simulation steps of vapor-liquid contact equipment, including that one used for ethanol + biodiesel systems.

Table 3. Fatty acid composition adopted for biodiesel from soybean oil (SB) and frying oil (FB).

\begin{tabular}{ccccc}
\hline \multirow{2}{*}{ FAAE $^{\mathrm{a}}$} & \multicolumn{2}{c}{$\mathrm{SB}(\mathrm{FAME})^{\mathrm{a}}$} & \multicolumn{2}{c}{ FB (FAEE) } \\
\cline { 2 - 5 } & $M /(\mathrm{g} / \mathrm{mol})^{\mathrm{c}}$ & $w / \%^{\mathrm{d}}$ & $M /(\mathrm{g} / \mathrm{mol})^{\mathrm{c}}$ & $w / \%^{\mathrm{d}}$ \\
\hline $\mathrm{C} 16: 0^{\mathrm{b}}$ & 270.45 & 11.1 & 284.48 & 12.0 \\
$\mathrm{C} 16: 1$ & - & - & 282.46 & 0.8 \\
$\mathrm{C} 18: 0$ & 298.5 & 4.0 & - & - \\
$\mathrm{C} 18: 1$ & 296.49 & 23.2 & 310.51 & 53.1 \\
$\mathrm{C} 18: 2$ & 294.47 & 53.6 & 308.50 & 33.1 \\
$\mathrm{C} 18: 3$ & 292.46 & 8.1 & 306.48 & 1.0 \\
& Overall: & 100 & Overall: & 100 \\
\hline
\end{tabular}

${ }^{a}$ FAAE, FAME and FAEE mean fatty acid alkyl, methyl and ethyl esters;

${ }^{\text {b}}$ The two numbers separated by a colon stand for the carbon chain length and number of double bonds;

${ }^{\mathrm{c}} M$ is molar mass;

${ }^{\mathrm{d}} W$ is mass fraction.

Table 4. NRTL binary interaction parameters for the systems studied.

\begin{tabular}{cccc}
\hline System ethanol (1) plus & $A_{i j} / \mathrm{K}$ & $A_{i j} / \mathrm{K}$ & $\alpha_{i j}=\alpha_{j i}$ \\
\hline Water (2) & 120.17 & 471.34 & 0.47 \\
Soybean oil biodiesel (3) & 4122.70 & 618.56 & 0.34 \\
Frying oil biodiesel (4) & 2510.70 & 486.55 & 0.45 \\
\hline
\end{tabular}

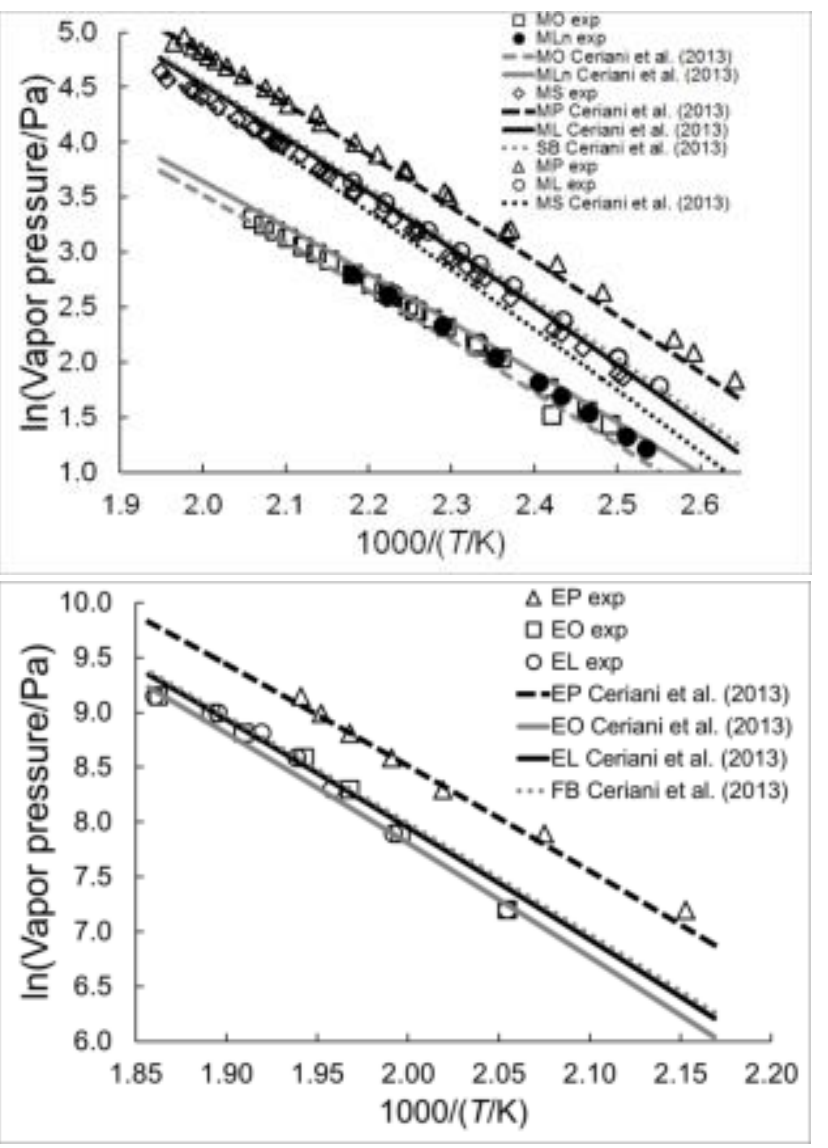

Figure 4. Experimental [29-33] and predicted vapor pressure for (a) methyl esters and biodiesel from soybean oil (SB); (b) ethyl esters and biodiesel from frying oil (FB).

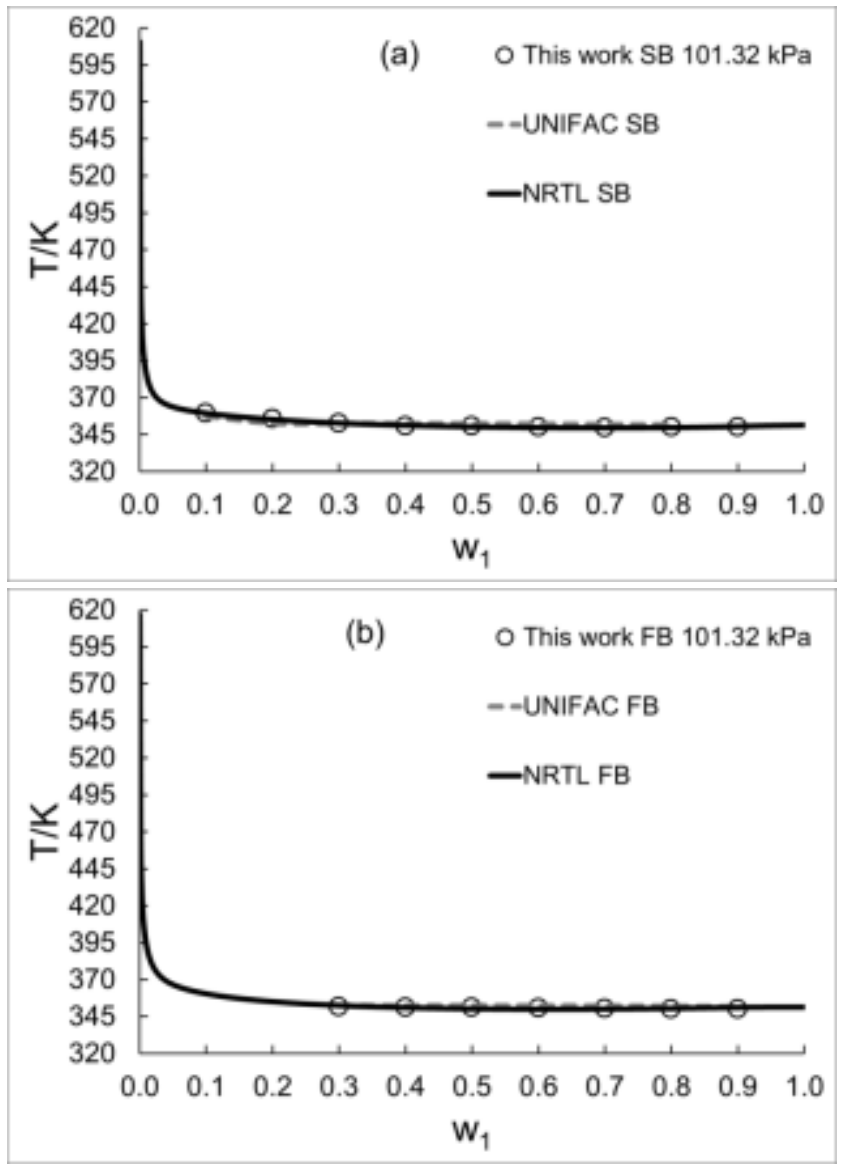

Figure 5. Experimental and calculated bubble-point temperature data using UNIFAC and NRTL models for systems (a) ethanol $+S B$ and $(b)$ ethanol $+F B$.

\section{Conclusions}

Vapor-liquid equilibrium data for mixtures of ethanol + biodiesel from soybean oil and ethanol + biodiesel from frying oil at $101.32 \mathrm{kPa}$ were measured. The boiling temperatures in composition charts showed that VLE data agreed with reported data for soybean oil and sunflower seed oil under similar pressure conditions. The thermodynamic modelling using the NRTL model obtained low $A A D$ values, assuring better safety conditions in the design and simulation steps for a biodiesel production plant.

\section{Acknowledgements}

The authors would like to acknowledge CNPQ and FINEP for financial support. P. M. K. and A. A. A. are also grateful to CAPES for the $\mathrm{PhD}$ scholarship.

\section{Nomenclature}

$A A D \quad$ Average absolute deviation

$A A D(P) \quad$ AAD relative to pressure $(\mathrm{kPa})$

$A A D(T) \quad$ AAD relative to temperature (K)

$A A D(y) \quad$ AAD relative to vapor composition (mole fraction)

$A_{i j} \quad$ NRTL binary interaction parameter between $i$-th and $j$-th components $(\mathrm{K})$ Molar mass (g/mol)

$N \quad$ Number of experimental points

$O F \quad$ Objective function 


$\begin{array}{ll}P & \text { Total pressure }(\mathrm{kPa}) \\ P_{i}^{\text {vap }} & \text { Vapor pressure of } i \text {-th component }(\mathrm{kPa}) \\ P_{n} & \text { Pressure at } n \text {-th experimental point } \\ T & \text { Temperature }(\mathrm{K}) \\ V_{n} & \text { Variable at } n \text {-th experimental point } \\ V_{n}^{\text {exp }} & \text { Experimental value of variable at } n \text {-th } \\ & \text { experimental point } \\ V_{n}^{\text {cal }} & \text { Calculated value of variable at } n \text {-th } \\ & \text { experimental point } \\ w_{i} & \text { Mass fraction of } i \text {-th component } \\ x_{i} & \text { Liquid mole fraction of } i \text {-th component } \\ y_{i} & \text { Vapor mole fraction of } i \text {-th component } \\ y_{i, n} & \text { Vapor mole fraction of } \mathrm{i} \text {-th component at } \\ & n \text {-th experimental point }\end{array}$

Greek symbols

$\begin{array}{ll}\alpha_{i j} & \begin{array}{l}\text { NRTL non-randomness parameter between } \\ i \text {-th and } j \text {-th components }\end{array} \\ \gamma_{i} & \text { Component activity coefficient } \\ \sigma_{P} & \text { Uncertainty observed in } P(\mathrm{kPa}) \\ \sigma_{T} & \text { Uncertainty observed in } T(\mathrm{~K}) \\ \sigma_{x} & \text { Uncertainty observed in } x \\ \sigma_{y} & \text { Uncertainty observed in } y\end{array}$

Abbreviations

EL Ethyl linoleate

EO Ethyl oleate

EP Ethyl palmitate

FAAE Fatty acid alkyl esters

FAEE Fatty acid ethyl esters

FAME Fatty acid methyl esters

FB Biodiesel from frying oil (frying biodiesel)

FID Flame ionization detector

GC Gas Chromatography

ML Methyl linoleate

MLn Methyl linolenate

MO Methyl oleate

MP Methyl palmitate

MS Methyl stearate

NRTL Non-Random Two-Liquid

SB Biodiesel from soybean oil (soybean biodiesel)

SSB Biodiesel from sunflower seed oil (sunflower seed biodiesel)

UNIFAC Universal Functional-Group Activity Coefficient

VLE Vapor-liquid equilibrium

\section{Appendix}

Table A1. Experimental isobaric boiling points for mixtures of ethanol + biodiesel from soybean oil and frying oil.

\begin{tabular}{cccc}
\hline \multicolumn{2}{c}{ Ethanol $+\mathrm{SB}$} & \multicolumn{2}{c}{ Ethanol + FB } \\
\hline $\mathrm{T} / \mathrm{K}^{\mathrm{a}}$ & $\mathrm{x}_{1}{ }^{\mathrm{b}}$ & $\mathrm{T} / \mathrm{K}^{\mathrm{a}}$ & $\mathrm{x}_{1}{ }^{\mathrm{c}}$ \\
359.55 & 0.4134 & 351.61 & 0.7402 \\
355.63 & 0.6132 & 351.08 & 0.8159 \\
352.55 & 0.7310 & 351.04 & 0.8692 \\
351.01 & 0.8088 & 350.76 & 0.9088 \\
350.65 & 0.8638 & 350.43 & 0.9394 \\
350.24 & 0.9049 & 350.03 & 0.9638 \\
349.75 & 0.9367 & 350.02 & 0.9836 \\
349.94 & 0.9621 & & \\
350.11 & 0.9828 & & \\
\hline
\end{tabular}

a Temperature uncertainty was $\sigma_{T}=0.10 \mathrm{~K} \mathrm{[34];}$

${ }^{\mathrm{b}}$ Component liquid mole fractions were $\sigma_{x_{1}}=\sigma_{x_{2}}=0.0023$ [34];

${ }^{\mathrm{c}}$ Component liquid mole fractions were $\sigma_{x_{1}}=\sigma_{x_{2}}=0.0017$ [34].

\section{References}

[1] M. Balat, H. Balat, "A critical review of bio-diesel as a vehicular fuel," Energy Conversion and Management, 49, 2727-2741, 2008.

[2] A. Gnanaprakasam, V. M. Sivakumar, A. Surendhar, M. Thirumarimurugan, T. Kannadasan, "Recent strategy of biodiesel production from waste cooking oil and process influencing parameters: a review," Journal of Energy, 2013, 2013.

[3] A. A. Albuquerque, L. Danielski, L. Stragevitch, "Techno-economic assessment of an alternative process for biodiesel production from feedstock containing high levels of free fatty acids," Energy \& Fuels, 30, 9409-9418, 2016.

[4] Y. Zhang, M. Dube, D. McLean, M. Kates, "Biodiesel production from waste cooking oil: 1. Process design and technological assessment," Bioresource Technology, 89, 1-16, 2003.

[5] A. Amelio, L. Loise, R. Azhandeh, S. Darvishmanesh, V. Calabró, J. Degrève, P. Luis, B. Van der Bruggen, "Purification of biodiesel using a membrane contactor: Liquid-liquid extraction," Fuel Processing Technology, 142, 352-360, 2016.

[6] R. Coelho, P. G. Dos Santos, M. R. Mafra, L. CardozoFilho, M. L. Corazza, "(Vapor+ liquid) equilibrium for the binary systems $\{$ water+ glycerol $\}$ and ethanol+ glycerol, ethyl stearate, and ethyl palmitate $\}$ at low pressures," The Journal of Chemical Thermodynamics, 43, 1870-1876, 2011.

[7] A. F. Young, F. L. Pessoa, E. M. Queiroz, "Comparison between Biodiesel Production from Soybean Oil and Palm Oil with Ethanol: Design and Economic Evaluation," Chem. Eng. Trans., 43, 325-330, 2015.

[8] L. A. Follegatti-Romero, M. B. Oliveira, F. R. Batista, E. A. Batista, J. A. Coutinho, A. J. Meirelles, "Liquidliquid equilibria for ternary systems containing ethyl esters, ethanol and glycerol at 323.15 and $353.15 \mathrm{~K}$," Fuel, 94, 386-394, 2012.

[9] L. Meher, D. V. Sagar, S. Naik, "Technical aspects of biodiesel production by transesterification-a review," Renewable and Sustainable Energy Reviews, 10, 248268, 2006. 
[10] J. Marchetti, V. Miguel, A. Errazu, "Possible methods for biodiesel production," Renewable and Sustainable Energy Reviews, 11, 1300-1311, 2007.

[11] D. I. S. Silva, M. R. Mafra, F. R. Silva, P. M. Ndiaye, L. P. Ramos, L. Cardozo Filho, M. L. Corazza, "Liquid-liquid and vapor-liquid equilibrium data for biodiesel reaction-separation systems," Fuel, 108, 269276, 2013.

[12] F. Ma, M. A. Hanna, "Biodiesel production: a review," Bioresource Technology, 70, 1-15, 1999.

[13] J. Žaglinskis, K. Lukács, Á. Bereczky, "Comparison of properties of a compression ignition engine operating on diesel-biodiesel blend with methanol additive," Fuel, 2016.

[14] M. Archer, A. Szklo, "Can increasing gasoline supply in the United States affect ethanol production in Brazil?," Renewable Energy, 95, 586-596, 2016.

[15] Y. Guo, J. Zhong, Y. Xing, D. Li, R. Lin, "Volatility of blended fuel of biodiesel and ethanol," Energy \& Fuels, 21, 1188-1192, 2007.

[16] A. Fredenslund, R. L. Jones, J. M. Prausnitz, "Groupcontribution estimation of activity coefficients in nonideal liquid mixtures," AIChE Journal, 21, 10861099, 1975.

[17] H. Renon, J. M. Prausnitz, "Local compositions in thermodynamic excess functions for liquid mixtures," AIChE Journal, 14, 135-144, 1968.

[18] K. Colombo, L. Ender, A. A. C. Barros, "The study of biodiesel production using $\mathrm{CaO}$ as a heterogeneous catalytic reaction," Egypt. J. Petrol, In Press, 2016. DOI: https://doi.org/10.1016/j.ejpe.2016.05.006

[19]T. M. Peruzzolo, V. R. Wiggers, H. F. Meier, E. L. Simionatto, D. R. Scharf, L. Ender, "Biodiesel production by homogeneous transesterification via reactive distillation column," Blucher Chemical Engineering Proceedings, 1, 1567-11573, 2014. DOI: 10.5151/chemeng-cobeq2014-0574-24881-165851

[20] F. Labor-UND, Manual of operation of the apparatus Fischer 10, 602. 1997.

[21] C. S. M. Gomes, H. N. M. de Oliveira, O. ChiavoneFilho, E. L. Foletto, "Vapor-liquid equilibria for ethyl acetate + methanol and ethyl acetate + ethanol mixtures: Experimental verification and prediction," Chemical Engineering Research and Design, 92, 28612866, 2014.

[22] J. M. Smith, H. C. Van Ness, M. M. Abbott, Introduction to chemical engineering thermodynamics. 7 ed. McGraw-Hill, 2005.

[23] L. Stragevitch, S. d'Avila, "Application of a generalized maximum likelihood method in the reduction of multicomponent liquid-liquid equilibrium data," Brazilian Journal of Chemical Engineering, 14, 1997. DOI: 10.1590/S0104-66321997000100004

[24] E. Herington, "A thermodynamic test for the internal consistency of experimental data on volatility ratios," Nature, 160, 610-611, 1947.

[25] O. Redlich, A. Kister, "Algebraic representation of thermodynamic properties and the classification of solutions," Industrial \& Engineering Chemistry, 40, 345-348, 1948.

[26] K. Iwakabe, H. Kosuge, "Isobaric vapor-liquid-liquid equilibria with a newly developed still," Fluid Phase Equilibria, 192, 171-186, 2001.
[27] R. Ceriani, R. Gani, Y. Liu, "Prediction of vapor pressure and heats of vaporization of edible oil/fat compounds by group contribution," Fluid Phase Equilibria, 337, 53-59, 2013.

[28] R. Alcantara, J. Amores, L. t. Canoira, E. Fidalgo, M. Franco, A. Navarro, "Catalytic production of biodiesel from soy-bean oil, used frying oil and tallow," Biomass and Bioenergy, 18, 515-527, 2000.

[29] C. W. Bonhorst, P. M. Althouse, H. O. Triebold, "Esters of naturally occurring fatty acids-physical properties of methyl, propyl, and isopropyl esters of C6 to C18 saturated fatty acids," Industrial \& Engineering Chemistry, 40, 2379-2384, 1948.

[30] T. A. Scott, D. Macmillan, E. H. Melvin, "Vapor pressures and distillation of methyl esters of some fatty acids," Industrial \& Engineering Chemistry, 44, 172$175,1952$.

[31] A. Rose, W. R. Supina, "Vapor Pressure and VaporLiquid Equilibrium Data for Methyl Esters of the Common Saturated Normal Fatty Acids," Journal of Chemical and Engineering Data, 6, 173-179, 1961.

[32] A. Rose, V. N. Schrodt, "Vapor-Liquid Equilibria for the Methyl Oleate and Methyl Stearate Binary System," Journal of Chemical \& Engineering Data, 9, 12-16, 1964.

[33] L. Y. A. Silva, R. M. M. Falleiro, A. J. A. Meirelles, M. A. Kraehenbuehl, "Determination of the vapor pressure of ethyl esters by Differential Scanning Calorimetry," The Journal of Chemical Thermodynamics, 43, 943-947, 2011.

[34] ABNT, INMETRO, Guide to the Expression of Uncertainty in Measurement (in portuguese). 3 ed. Brazil: SERIFA Comunicação, 2003. 